\title{
Financial innovation and climate change: the case of renewable energy certificates and the role of the GATS
}

\author{
PANAGIOTIS DELIMATSIS* \\ Assistant Professor of Law, Tilburg University, Netherlands and Senior Research Fellow, World Trade Institute, \\ Switzerland
}

\begin{abstract}
Energy has come to the forefront of the public debate in the past decade for two main reasons: the first relates to the lack of a secure, continuous, and unconditional energy supply in the importing countries, mostly developed and transition economies, which are still dependent on non-renewable carbon-based fossil fuels. The second reason is that uncontrolled production, distribution, and use of conventional energy may lead to environmental degradation and global warming. Renewable energy certificates (RECs) are instruments that allow countries to promote energy generation from renewables and form part of domestic policies aimed at climate change mitigation and adaptation. Since RECs can be traded in secondary markets, this paper discusses issues raised by the nature of and the trade in RECs which can be of concern for the General Agreement on Trade in Services (GATS) and the multilateral regulation of trade in financial services, notably in the case where World Trade Organisation (WTO) Members undertook sweeping commitments in financial services which equally apply to trade in RECs.
\end{abstract}

\section{Introductory remarks}

Energy production and distribution constitute the biggest business in the world economy, with a turnover of approximately US\$ 1,7-2 trillion on an annual basis (UNCTAD, 2001: 3) with energy demand mounting (IEA, 2007: 4). The quest for sufficient and diversified energy supplies which will ensure economic sustainability and energy security has become part and parcel of foreign policy. In most cases, such energy security is achieved through the import of energy produced from conventional energy sources. Nowadays, fossil fuels account for around $87 \%$ of global energy consumption. Yet, several studies have unequivocally highlighted the deleterious impact of fossil fuels on the environment and the urgent need to introduce low-carbon emitting energy technologies and to develop renewable energy sources (RES) (IPCC, 2007: 36-41).

\footnotetext{
*Email: p.delimatsis@uvt.nl

Many thanks go to the Members of the Tilburg Law and Economics Center (TILEC), Alan Winters, and the two anonymous referees of the World Trade Review for thoughtful insights and stimulating discussions. All remaining errors are of the author's alone.
} 
Recognizing that the negative externalities go beyond national borders (Stern, 2006: 27), several multilateral instruments have been adopted to achieve climate change mitigation in the last two decades (Freestone, 2005: 3). The United Nations Framework Convention on Climate Change (UNFCCC) in $1992^{1}$ and the ensuing adoption of the Kyoto Protocol in $1997^{2}$ are the most prominent instruments to date that have attempted to tackle the negative impact of anthropogenic emissions of carbon dioxide and other gases on the atmosphere. Quite modestly, the UNFCCC aims to stabilize greenhouse gas (GHG) emissions at a level that prevents any anthropogenic interference with the climate system. ${ }^{3}$ The Kyoto Protocol to the UNFCCC is however more ambitious in that it sets up the framework for the first-ever global, market-based scheme aimed at reducing emissions through trading of emission rights. In this respect, industrialized countries have agreed on binding and enforceable obligations and emission reduction commitments. ${ }^{4}$ More recently, in Bali, countries recognized that a new international agreement which enables and supports long-term (i.e. post-2012) co-operative action is warranted for a smooth transition to a low-carbon and sustainable economy. ${ }^{\mathbf{5}}$ Acknowledging the conflicts that the co-existence of the UNFCCC and the multilateral trading system may bring about, the Convention provides in its Article 3:5 that actions to tackle climate change, notably taken at the unilateral level 'should not constitute a means of arbitrary or unjustifiable discrimination or a disguised restriction on international trade'. In addition, Article 2:3 of the Kyoto Protocol requires that its parties 'strive to implement policies and measures [that reduce GHG emissions] ... in such a way as to minimize adverse effects, including ... effects on international trade'.

Regarding climate change mitigation and adaptation, the recent erosion of State involvement has led to the indispensable participation of the private sector in the implementation of mechanisms and projects addressing energy and climate change- or environment-related issues (Green, 2005: 149; UNEP 2007: 483). In recent years, several innovative market-based schemes that allow trading of units, rights, credits, allowances, or certificates have appeared. For our purposes, a distinction should be made between, on the one side, schemes allowing the trading of emission rights or allowances such as the Kyoto Protocol or the EU Emission Trading Directive (Directive 2003/87/EC; European Commission, 2008a), which

\footnotetext{
1 Reprinted in 31 International Legal Materials (1992), 851, entered into force on 21 March 1994. According to the Convention, climate change refers to a change of climate that is 'attributed directly or indirectly to human activity that alters the composition of the global atmosphere and which is in addition to natural climate variability observed over comparable time periods'. UNFCCC, Art. 1:2.

2 UNFCCC, 'Kyoto Protocol to the United Nations Framework Convention on Climate Change', FCCC/CP/1997/L.7/Add.1, reprinted in 37 International Legal Materials (1998), 22. The Kyoto Protocol was adopted in March 1998 by 186 countries (Decision 1/CP.3) and entered into force on 16 February 2005 .
}

3 UNFCCC, Art. 2.

4 These countries are listed in Annex I of the UNFCCC.

5 UNFCCC, ‘Bali Action Plan', Decision 1/CP.13. 
aim at the reduction of GHG emissions, and, on the other side, schemes that set up the framework for the trade of renewable energy (or 'green') credits or certificates, which aim at the promotion of energy production from RES.

Because RECs are tradable on the financial markets, a question that arises relates to the applicability to such transactions of the WTO rules and notably those set out in the GATS and the Financial Services Annex. While the WTO Agreements do not have specific rules addressing environmental or climate change-related issues, trade rules and State or State-induced actions to combat climate change interact and may clash with one another. In addition, non-WTO multilateral rules tackling climate change and increasing environmental awareness will inform interpretations by the WTO judiciary. ${ }^{6}$ Furthermore, the WTO Members, already during the Uruguay Round, appear to have been 'fully aware of the importance and legitimacy of environmental protection as a goal of national and international policy' and the significance of promoting sustainable development, as the Preamble of the WTO agreement demonstrates. ${ }^{7}$ It bears mention that Article 3:4 of the UNFCCC refers to the right, which at the same time constitutes an obligation, to promote sustainable development.

Section 1 provides a brief overview of the international regulation of trade in financial services under the GATS. The mechanics of trading in 'green' certificates and their relationship with emission trading under the Kyoto Protocol will be analysed in Section 2. Section 3 deals with the alleged dichotomy between trading in emission allowances and trading in RECs, while Section 4 examines REC trading more closely. In Section 5, an attempt is made to classify certificates as financial instruments which come under the definition of financial services in the Financial Services Annex to the GATS. Section 6 concludes.

\section{GATS and financial services}

A growing body of empirical studies demonstrates a strong positive link between the expansion of financial services and long-term economic growth, and positive spillovers vis-à-vis other sectors of the economy (Eschenbach et al., 2000: 103). Owing to the importance of the financial sector, governments interfere with financial markets extensively to reduce systemic risk and enhance the safety and soundness of the financial system (Gilligan, 1999: 37). Since the financial sector is often considered sui generis due to its 'public goods' characteristics, it seems, in principle, that governmental intervention is justifiable (WTO, 1998b: 9). Again, economic research has demonstrated that further liberalization of financial services can have important growth-generating effects (Mattoo et al., 2006).

Trade in financial services has experienced rapid growth in recent years. Technological progress in communications, the spread of information technology

6 Appellate Body Report, US-Shrimp, WT/DS58/AB/R, DSR 1998: VII, 2755, para. 153.

7 Ibid, para. 129. 
and electronic data processing, the internet-based supply of financial services, and the unprecedented levels of multilateral trade liberalization have given a fillip to its expansion, particularly in a cross-border manner (Mode 1 in the GATS parlance) (Claessens, 2003: 130-1, 135). Additionally, the boundaries between financial and non-financial institutions are becoming increasingly blurred, as non-banks, such as telecommunication companies, utilities, or retail chains, have entered the retail financial markets and provide several types of financial services. Technological advances also allowed remote trading. The supply of trading services is no longer bound to occur in any physical exchange and thus the need for local presence is diminishing. These changes, along with flexible regulation in certain cases, have also led to innovative industry structures and products, notably in those categories of financial services such as brokerage, trading systems or retail banking that could be unbundled and commoditized easily, offering appealing initial profit margins. All these factors have coalesced to increase the significance of the financial sector for the economy overall and improve the conduct of business in this sector in terms of costs and efficiency.

Financial services were at the heart of the GATS negotiations during the Uruguay Round (Bhagwati, 1984: 140). Negotiations were ultimately concluded in December 1997 through the adoption of the Fifth Protocol, thereby resulting in the full integration of financial services into the GATS (WTO, 1997). The Protocol entered into force in March 1999, four years after the establishment of the WTO and only a few months before the beginning of the new Round of services negotiations pursuant to Article XIX GATS. For WTO Members that accepted the Fifth Protocol after March 1999, commitments entered into force upon acceptance. ${ }^{8}$ By the conclusion of the negotiations, over 100 WTO Members had made legally binding commitments in financial services, the second highest number after tourism. All developed countries undertook commitments in all sub-sectors of financial services, whereas developing economies opted for scheduling commitments relating to insurance and banking services rather than to capital market-related services such as securities trading, underwriting, and asset management.

In scheduling commitments in the financial sector, several Members, mostly OECD countries, used the Understanding on Commitments in Financial Services (hereinafter the 'Understanding'), an optional, auxiliary text containing a 'formula' approach for scheduling commitments (Wilkinson, 1995: 415; WTO, 2002: 18; Key, 2005: 985). The Understanding provides an à la carte approach to scheduling which deviates from the approach provided in Part III of the GATS. ${ }^{9}$ With its predetermined set of commitments, it has led to deeper commitments in the sector and was incorporated into the Schedules of Commitments of around

8 Commitments may not yet have been implemented in the absence of formal ratification of the Protocol according to the domestic legal order. This is, for instance, the case of Brazil.

9 From a legal viewpoint, the Understanding is a unique WTO document, as it was included in the Final Act of the Uruguay Round but does not form an integral part of the GATS. 
30 Members (counting the EC 15 as one) on an MFN basis (Woodrow, 2000: 78). The Understanding requires the binding of the status quo, adopts a negative-list approach to scheduling commitments (albeit only regarding commitments on commercial presence), and embodies a standstill commitment as well as broad liberalization commitments relating to market access, national treatment, government procurement, and the offer of new financial services. ${ }^{10}$ On the other side, the Understanding does not prevent a Member from adding any limitations on market access and/or national treatment even if it undertook commitments in the financial sector based on the Understanding.

The commitments undertaken did nothing else than locking in the status quo in most markets during that period (Roy et al., 2008: 87). Severe restrictions on the number of suppliers, the legal form of commercial presence, or the participation of foreign equity remained, whereas Members were even more reluctant to liberalize cross-border supply.

\section{RECs: definition, scope, context, mechanics}

RECs are innovative instruments for the development of clean energy technologies to combat climate change and facilitate the diversification of a country's energy supply. Eligible RES can be, inter alia, wind power, biomass, biodiesel, solar power, wave power, and small-scale hydropower. Increasing the use of RES constitutes a key priority for several countries, also in accordance with their internal legislative acts which, in turn, aim to implement international obligations. ${ }^{11}$ Trade in environmental commodities such as RECs is conducive to achieving this goal. A REC system is based on a government's decision to promote the use of renewable electricity through a renewable energy quota obligation (e.g. $15 \%$ of the electricity portfolio of a producer or distributor). This quota obligation is administered by a system of tradable RECs. A REC ${ }^{12}$ is typically issued when one MWh of electricity is produced from a qualified RES. It takes the form of an electronic record administered through software that allows the issuance, tracking, and registration of RECs, which are deposited and withdrawn in a central electronic registry of accounts of RES generators. ${ }^{13}$ Hence, RECs are intangible,

10 Paragraph B.7 and D.3 of the Understanding. The purpose of this provision, which was strongly supported by the US financial services industry, is to allow innovative products introduced by financial institutions in their home countries - and approved by the competent home-country authorities - also to be introduced by their offices in the host countries, even if these services are not yet supplied in these jurisdictions.

11 ECJ Case C-379/98, PreussenElektra [2001] ECR I-2099, para. 74.

12 Depending on the country at issue, RECs are also known as green tags, renewable energy credits, renewables obligation certificates, tradable green certificates, or, in the US, as Renewable Portfolio Standards. In the EU parlance, RECs are known as Guarantees of Origin.

13 A REC will more often than not include the following information: a unique ID number; information about the producer; the date of issuance and the period of production that led to the issuance of this REC; unit and amount; the location and capacity of the plant; the RES used; its expiration date, if 
tradable financial assets reflecting the value created by unbundling the environmental attributes of one MWh of electricity from a RES (Gillenwater, 2008a: 2109). The possession of a specific number of RECs confirms that a supplier or distribution company has complied with the minimum share obligation. Once a year the RECs are redeemed and the competent authority verifies the compliance of the producers and distributors with their obligations. In the case of noncompliance, the responsible producer or distributor can be fined.

A REC scheme promotes clean energy investment in that a RES generator benefits from two different sources of income: the first stems from vending the physical electricity produced on the grid at the market price, while the second is associated with the number of 'green' certificates that it sells and corresponds to the renewable energy produced. The possession of a REC is a piece of evidence that entitles its holder to receive financial support, which consists of the additional income generated through the sale of the green certificate. This second source of income can be seen as a reward for the environmental benefits that renewable energy technologies generate vis-à-vis conventional energy sources (Morthorst, 2000: 1086).

Since RECs can be unbundled from the underlying physical electricity and traded independently in their electronic form, ${ }^{14}$ electricity suppliers, distribution companies, or even consumers, depending on the relevant legislation in force, have the possibility to purchase only the environmental attributes of electricity that was produced elsewhere. The 'trading potential' of RECs allows financial service suppliers to broker the finalization of the relevant trades. Thus, the 'green' attributes of RECs can be sold anywhere provided that the countries involved mutually recognize their tradable REC systems so that RECs issued abroad can be used to comply with the domestic minimum share obligation (Söderholm, 2008: 2057; European Commission, 2008a: Art. 5:9). Ultimately, the renewable energy is produced somewhere on the globe and therefore the positive impact on the environment will occur.

For instance, pursuant to the EU Renewables Directive in force (Directive 2001/87/EC), aside from the overall EU target of $21 \%$ of electricity generation stemming from RES by 2010, each EU Member State (MS) has committed to meeting individual national targets to this end. Importation of RES-E produced in another MS would be possible in order for the importing MS to meet its national target. In this case, a guarantee of origin, that is a proof of the green nature of the electricity, would ensure the avoidance of double counting of the energy produced.

applicable; the support or investment aid received for the production of renewable energy; and the environmental benefit, that is how much pollution has been avoided due to the use of renewables in the production of electricity. Also European Commission (2008a), Art. 6:2 of the proposed Directive on renewables promotion. This information allows double counting to be avoided and offers protection against erroneous guarantees of origin.

14 RECs can exceptionally be sold bundled with the underlying physical electricity. Such a requirement may be imposed to promote local generation of RES. Holt and Wiser (2007: 3). 
In this respect, the directive calls for the establishment at the national level of the necessary mechanisms for the issue and mutual recognition of guarantees of origin regarding electricity generated in another MS. ${ }^{15}$

RECs can also be bought, for instance, by environmental groups or environmentally aware individuals, to support financially the development of RES. Individual companies can also buy RECs in an attempt to strengthen their environmental-friendly profile. RECs can also be part of industry-driven, voluntary environmental-friendly markets that aim to promote RES, e.g. in the context of companies' corporate social responsibility (CSR) programs.

REC prices may depend on the location of the facility producing the certificates, the type of RES and the power created; the supply and demand situation; the level of penalties for non-compliance, or even whether the certificate will be used by the purchaser to comply with a renewables minimum share obligation. ${ }^{16}$ Research shows that REC prices can fluctuate significantly, especially when the minimum share (quota) is set too high (Meyer, 2003: 669). This insecurity may deter potential investors from entering the market of renewables (Mitchell et al., 2006: 297). This, in turn, would lead to a small number of participants and an ensuing lack of liquidity, that is thin trading. Price volatility can be neutralized through the use of derivatives, e.g. futures with long-term contracts that would estimate the profitability of the projects at issue, or by allowing intertemporal trading, that is borrowing and banking. This would allow the transfer of certificates to the coming years in case of excess supply or in the presence of speculations for higher prices in the future for such certificates (banking) or the acquisition of more certificates than a producer, distribution company, or consumer actually needs when the price is low so that they are able to cover renewables obligations in the future (borrowing).

Another way of avoiding unpredictable fluctuations is the adoption by the regulator of minimum and maximum prices for certificates (Menanteau et al., 2003: 810). While maximum prices (ceilings) would be necessary to avoid abuses in case of a shortage of RECs, minimum guaranteed prices (floors) are equally important for the short-term viability of projects entailing renewables at this initial stage of RES development. Demand of course is crucial and is typically created through the imposition of a minimum purchase obligation on the consumers. Increasing environmental awareness of consumers is also expected to create additional demand for electricity generated from RES. In addition, the fact that the certificates issued can be traded either bilaterally or through the already established financial markets may lead to cost-efficient production of renewable energy by the generators that use renewables technology. Finally, the size of a market is decisive. Bigger markets can counterbalance the shortage of liquidity, narrow spreads and allow for a more cost-efficient development of renewable

15 Article 5 of the Directive. Also C-379/98, PreussenElektra, above note 11, para. 80.

16 Indeed, compliance markets offer better options for REC trading than voluntary markets. UNEP Finance Initiative (2002), 25. 
energy plants with optimal allocation of available resources for the highest possible production of energy (Verhaegen et al., 2005: 459). Therefore, several countries, notably in Europe, are looking at the possibility of linking their REC system with similar systems in other countries. For such linkage to be successful, careful monitoring is needed to avoid double counting and to ensure the issuance of reliable guarantees of origin. In the medium or long run, regional markets or even an international market for RECs could emerge.

Setting the conditions for a well-functioning exchange of RECs can imply high administrative costs. It would involve the creation of a mechanism that certifies that the producers generate energy from RES and issue certificates, and thereafter monitor and control these processes; the establishment of a registry where certificates would be stored electronically and attributed a unique ID number; careful accounting and auditing to avoid, inter alia, double counting; and a surveillance mechanism that would lead to the imposition of penalties whenever the obligations of the RES producers vis-à-vis minimum energy generation from RES were not met. Other drawbacks of REC systems may include the absence of fair competition when different technologies (for instance, wind and solar energy), which entail lower setup and operational costs than other RES, enjoy the same level of governmental support. Finally, the inherent complexity and the high transaction costs of REC systems may discourage small-scale producers of renewables and ultimately allow oligopolistic behaviour to flourish (Agnolucci, 2007: 3348).

\section{The dichotomy between emission trading and trading in RECs}

Article 17 of the Kyoto Protocol provides the framework for the first global scheme of trading of emission rights for use in the fight against the global warming potential of GHG emissions (de Witt Wijnen, 2005: 403). For the countries that ratified the Kyoto Protocol, there is a set of legally binding emission limits and commitments to reduce GHG emissions. Several countries that ratified the Protocol adopted market-based mechanisms that would allow buying and selling of emissions allowances (Kyoto Units), the so-called emission trading scheme (ETS) (Wemaere and Streck, 2005: 44). The Protocol allows the reduction of emissions abroad and hence Parties can meet their commitments through the transfer or acquisition of Kyoto Units worldwide. ${ }^{17}$ Each Kyoto Unit, that is each entitlement to emit, represents one metric tonne of $\mathrm{CO}_{2}$ equivalent. ${ }^{18}$

17 Trading is also allowed in the other two GHG reduction systems of the Kyoto Protocol, that is the Joint Implementation (JI) and the Clean Development Mechanism (CDM). In 2007, almost two-thirds of the transacted volume in the CDM market stemmed from carbon contracts from clean energy (i.e. energy efficiency and renewable energy) projects. Capoor and Ambrosi (2008), 29.

$18 \mathrm{CO}_{2}$ equivalent is the universal unit of measurement used to indicate the global warming potential of each of the six GHGs, which are: carbon dioxide (1); methane (21); nitrous oxide (310); halocarbons (HFC) (140 to 11,700); and sulphur hexafluoride $(23,900)$. 
When compared to command-and-control instruments, emission trading is regarded as a cost-effective mechanism for reducing emissions. In this sense, an ETS complies with the overall objective of the UNFCCC of using cost-effective policies and measures to tackle climate change 'so as to ensure global benefits at the lowest possible cost'. ${ }^{19}$ The total size of the EU emission trading market alone is estimated at $€ 5-10$ billion per year (Dornau, 2005 : 417). Hence, services related to emission trading, such as brokerage, accounting, or verification is a new but very promising services sector. Again, at present, it appears that only large consulting firms and financial institutions from developed countries have the financial savvy to supply such services and frame deals among entities wishing to buy and sell emission rights. Thus, business opportunities are not yet evenly distributed between developed and developing countries. This lack of expertise on emission trading markets inevitably hampers developing countries' goal to achieve sustainable development notably through the CDM (UNCTAD, 2001: 18).

Whether trading in RECs squares nicely with an emission trading scheme is controversial (NERA Economic Consulting, 2005: 19). Interaction between the two systems could take two forms: First, it could mean merely that the two schemes co-exist, but second it could entail that companies could use the $\mathrm{CO}_{2}$ reductions that are implicit in a REC in order to comply with the obligations relating to emission reductions. While the first type of interaction would not pose any problems and in fact occurs in several jurisdictions, the second type of interaction is quite controversial and, in theory at least, may lead to double counting absent a sophisticated monitoring and accounting mechanism.

In the emission trading schemes, the tradable item is an entitlement to release a certain quantity of GHG emissions into the atmosphere. In a 'green' certificate market where RECs are traded, governments impose on the producers or distribution companies and retail suppliers the obligation that a minimum share of the electricity generated or supplied to the retail consumer stems from deployment of RES. Depending on the amount of electricity produced by such sources, producers receive a number of certificates which they can sell to potential buyers who cannot meet their aforementioned obligation.

The trading of RECs appears to be relatively open and there are several entities or individuals that can participate, from network and distribution companies to individuals and NGOs. Nevertheless, the ETS established by the Kyoto Protocol sets mandatory targets and thus international obligations for the States that are parties of the UNFCCC. Hence, even if entities are authorized to participate in transfers and acquisitions of emission rights under Article 17 of the Kyoto Protocol, it is the Parties to the Protocol that are responsible for fulfilling their obligations under international law and ensuring that the participation of private entities in the trading of emission rights is in line with the Parties' commitments and consistent with the applicable rules.

19 UNFCCC, Art. 3:3. 
For instance, the EU emission trading Directive (Directive 2003/87/EC) provides that transfer of emission allowances can take place: (i) between natural or legal persons within the EU, and (ii) between persons established in the EU and persons in countries listed in Annex B to the Kyoto Protocol and which have ratified the Protocol. ${ }^{20}$ For this, a previous agreement is required between the Community and the country listed regarding the mutual recognition of their respective emission trading schemes. However, the Directive and the emission trading it introduces are the means for the Community to achieve its emission limitation and reduction commitments stemming from the Kyoto Protocol.

At a policy level, a distinction is drawn between emission trading and REC schemes. Whereas REC schemes are both climate change mitigation and adaptation instruments, reduction of emissions is the main climate change mitigation tool. Again, this division may not be sustained so easily in practice. Furthermore, it holds true that both emission trading and 'green' certificate schemes essentially aim at the betterment of the environment by avoiding harmful emissions from fossil fuels; directly through setting emission caps in an ETS and indirectly through a REC scheme that promotes energy generation from RES. Another common feature of these two types of trading markets is that their potential is enormous, if developed properly. The future GHG credit trading market, for instance, is expected to grow from US\$64 billion in 2007 to over US\$3 trillion per year by 2020 (Point Carbon, 2008). Regarding the green certificate market, in the US alone the value of the market is expected to be over US\$700 million in 2010 (Holt and Bird, 2005: 2).

Arguably, then, 'green' certificates systems, when designed properly, are compatible and can co-exist with or be integrated into other schemes aiming at climate change mitigation, such as emission trading (Morthorst, 2001: 345; Gillenwater, 2008b : 2120). A REC system should be considered as a complement to an ETS. ${ }^{21}$ The latter can lead to the reduction of GHG emissions, but not necessarily to the expansion of the use of energy generated by renewables. A REC system, when carefully designed and implemented, can stimulate the generation of energy from RES and boost innovation. Viewed from this angle, then, an emission trading scheme and a system with RECs (or any other support scheme relating to RES) do not appear to be in conflict with one another.

\section{Trade in RECs and the supply of financial services}

As noted earlier, in a REC system, the electricity produced and its environmental attributes in the form of a 'green' certificate, that is its 'greenness', are detached at

20 Thus, US companies are in principle excluded from participating in this scheme. Nevertheless, US parent companies can effectively participate in emissions trading and supply related services, such as brokerage and verification services, through their subsidiaries established in the EU market through the 'single passport' rule. Art. V:6 GATS also corroborates this viewpoint. Also Wilder (2005: 257).

21 In 2007, 12 EU MS had in place a system based on RECs. REN21 (2007), 23. 
the point of energy generation from RES and traded individually. In REC trading, there are several actors that can participate: producers, distribution companies, NGOs, or, more broadly, entities that have to meet the minimum share obligation and thus need to submit a given number of certificates at the end of a pre-specified period. This latter category can also involve consumers, depending on the regulatory regime at issue. Brokers can also be allowed to participate in REC trading and directly buy or sell RECs on behalf of their clients. As REC trading typically occurs electronically, the existence of a registry where all participating entities maintain an account is essential. Because of the high level of expertise needed in the trading with transferable assets, brokers and traders play a central role in the final shape of any deal, notably when the number of certificates and, a fortiori, the amounts of money at stake are significant. They act as intermediaries to close deals between companies that have to fulfill a minimum quota obligation regarding energy produced from renewables. As the number of participants in trading grows, the monitoring and control of the actual trading becomes more difficult. On the other hand, a bigger market for RECs can ensure higher levels of liquidity, more reasonable and transparent prices with predictable fluctuations, and low probability of market manipulation (Agnolucci, 2007: 3348).

Simple rules for trading and the standardization of contracts also make the market attractive for many stakeholders. This, along with the creation of common standards regarding the information that a REC should include, could eventually lead to the mutual recognition of different REC systems or the harmonization and standardization of rules on the issuance, registration, verification, auditing, and redemption of RECs, with a view to creating a global REC system. Simplicity, non-discrimination, transparency, and objectivity are also elements that, if present in a REC scheme, would allow small- and medium-sized enterprises (SMEs) to participate as intermediaries in REC trading. Possibilities for the successful participation of SMEs should be expected to increase as the volumes of trade relating to renewables grow, since only considerable volumes will attract the interest of financial institutions so that they offer funding opportunities and suitable risk management products for small-scale sustainable energy companies.

REC trading can take place on a bilateral, ad hoc basis (over the counter-OTC). In this case, the amount of RECs traded can be significant. In bilateral trading, the RECs are sometimes sold together with the electricity produced. The transfer should be subsequently reported to the REC registry. This is not necessary when trading occurs through an electronic trading platform or an exchange in real time, e.g. in an electricity trading exchange, as the registry would be connected with the platform and would be notified of the transaction directly. Such a platform leads to higher levels of transparency and competition (Allen et al., 2001: 44). These two ways of REC trading are in competition with one another and are expected to reduce transaction costs.

Trading can involve direct purchases of certificates in primary markets, but it can also entail trading with derivatives which have underlying RECs in secondary 
markets. In the former case, there is a list of intermediary services involved such as brokerage or banking and insurance services. In the latter case, buyers and sellers exchange derivative products for investment purposes. For instance, transactions can include financial derivatives such as call options, according to which a company buys the right, but not the obligation to buy a specific quantity of certificates at a fixed price at a specified future date; or they can involve futures contracts. Both trading options can be attractive for financial service suppliers, as trading takes the form of standard commodity trading where the supply of the related financial services can also occur in a remote, including cross-border, manner. For the producers, such options are also very appealing, since they allow for predictability and better risk management.

As to the entities that will be authorized to be active in the trading with RECs, it is for the government, when designing the trading scheme, to establish clear eligibility criteria for the participating entities. For financial institutions and brokers, such criteria may include prior acquisition of a licence by the competent authority or prudential requirements such as capital adequacy and disclosure requirements or sufficient assets. They may also require the establishment of such entities in the territory of the country where the trading platform is set. It bears mention that, under the EU Directive on Financial Instruments (MiFID), MS are required to allow in their regulated markets, e.g. their power exchange, the participation of 'remote members', that is entities established in another MS. The Directive requires that MS make all the necessary arrangements to facilitate access to and use of their systems by such entities (Directive 2004/39/EC, Articles 31, 33, 42). As the MiFID establishes several requirements relating to brokerage/intermediation services and pre- as well as post-trading and RECs are tradable instruments of a financial nature, it is applicable to REC trading.

REC trading can raise several issues in need of clarification. For instance, the delimitation of competences between the supervising authorities of the two (or more) countries involved or the question of judicial review in the case of crossborder transfers. Both issues call for regulatory co-operation to protect investors and consumers. In situations like the ones just described, a regulatory approach that favours efficient and operational disclosure and investor protection rules appears to be a fairly rapid and adequate response. Again, the fact that much of this trade takes place through intermediaries established in a few global financial centres which have the savvy to finalize such transactions may facilitate the task of the regulators.

Another important issue is the taxability of transfers. Especially in OTC trading, the amounts of money involved can be significant and therefore tax authorities in both countries may be tempted to charge the tax for the transaction in their jurisdiction. Arguably, the price that the seller will get for the REC will be regarded as income and will be taxed accordingly. Because this could be considered as a disincentive to sell and thus could create problems to the proper functioning of a REC market, governments could set a lower tax for such transactions in the 
context of their strategy to promote renewables. However, if the taxation system does not treat such transactions differently, then the REC price will most likely reflect these charges.

\section{Issues of sectoral classification and the applicability of the GATS}

Until recently, energy-related services were supplied by state-owned vertically integrated monopolies either domestically or cross-border (WTO, 1998a). Hence, there was no scope for any trade whatsoever. However, as a result of intensive liberalization attempts, core energy services (e.g. transport, transmission, and distribution) were unbundled and are now provided by private entities (sometimes former public monopolies which have been privatized) under conditions of competition in many countries. This trend resulted in a great deal of confusion as to whether specific economic activities related to energy raise questions that should be dealt with under the GATT, the GATS, or both. ${ }^{22}$ It has also revealed possible imbalances that may appear due to this 'sorting out' of previously fused activities.

REC trading can raise several issues of relevance to the GATS and the regulation of trade in financial services. Energy or energy-related services is not a separate comprehensive category in the W/120, the Services Sectoral Classification List (GATT, 1991). The same is true for the United Nations Central Product Classification on which the W/120 is based. Instead, energy-related services, e.g. transport, distribution, construction, engineering, energy-related financial services, research and development, and consultancy are dispersed across several existing sectoral classifications within the W/120. Only three subsectors in the W/120 are energy-specific: pipeline transportation of fuels (under 'transport services'), services incidental to energy distribution, and services incidental to mining (under 'business services') (WTO, 1998a: 3). Of course, Members could deviate from the W/120 nomenclature and undertake commitments on a cluster of energy-related services. The 1993 Scheduling Guidelines clearly point to this possibility on condition that the scope of the commitment and of the classification used is sufficiently detailed to avoid any ambiguities. ${ }^{23}$ However, commitments on energy services were not a priority for most Members and thus negotiations focused on other areas. Overall, Members' commitments in energy-related services were limited at the closure of the Uruguay Round negotiations (Evans, 2003: 174).

Nevertheless, the privatization and deregulation of companies that are active in the energy industry, along with the current international focus on energy security and global warming, invigorate the discussion as to ways to go beyond the W/120 nomenclature to encapsulate contemporary market realities. Because the final

22 Consistent WTO case-law confirms that the two Agreements are not mutually exclusive. Appellate Body Report, EC-Bananas III, WT/DS27/AB/R, DSR 1997: II, 591, para. 221; also Appellate Body Report, Canada-Autos, WT/DS142/AB/R, DSR 2000: VI, 2985, paras. 159-166.

23 Also Appellate Body Report, US-Gambling, WT/DS285/AB/R, DSR 2005: XII, 5663 (Corr.1, DSR 2006: XII, 5475), paras. 202-203. 
consumption of energy is the outcome of a series of associated activities, market access may be a prerequisite in a considerable number of services sectors for energy service suppliers to provide their services adequately. This argument would call for the creation of a new entry in the Services Classification List that would allow Members to consider energy-related services as a cluster and undertake commitments that would facilitate the supply of such services by supplying effective market access on interrelated activities. As it stands, the current Classification List allows for inconsistencies and possible contradictions among sectors which can be considered as energy related. A cluster approach would allow a Member to clarify its level of openness with regard to energy services and undertake energy-specific commitments.

An approach confronting energy-related services as a cluster would also allow Members to undertake more ambitious commitments in energy-related financial services such as RES project financing or facilitated market access for SMEs providing exclusively trading services in the emission or REC markets. Such an approach would not render the Financial Services Annex irrelevant, but would merely allow Members to differentiate among supplied services and offer advantageous access to suppliers active in niche markets if they wish so.

For the time being, absent an entry that lists energy-related services separately, REC trading falls under the provisions of the Financial Services Annex to the GATS. According to the Financial Services Annex, financial services include any service of a financial nature provided by a financial service supplier, including all insurance and insurance-related services (e.g., direct insurance, insurance intermediation), as well as all banking and other financial services (e.g., deposit taking, lending, asset management and trading). ${ }^{24}$ The list of financial services is extensive but non-exhaustive. The classification used in paragraph 5 of the Annex is fairly broad and flexible. It should come as no surprise that Members consider this list to be relevant to the current services negotiations and they are encouraged to use this list rather than the W/120 (WTO, 2005).

Rationae personae, the Annex has a broad scope, as it applies to all natural or juridical persons who supply financial services, but it equally captures potential and prospective suppliers. ${ }^{25}$ Those juridical or natural persons who are not yet providing financial services in the territory of the prospective host country or even in the territory of the Member where they reside are also considered as financial service suppliers, and thus benefit from the rights that flow from the GATS. It stems that the GATS drafters intended to consider as financial service suppliers also those suppliers that are at the exploratory stage of a prospective commercial presence (Dobson and Jacquet, 1998: 100).

According to the Annex, only private entities can be considered as 'financial service suppliers'. Credit institutions, financial conglomerates, brokerage firms, 
insurance firms, and non-bank financial intermediaries provide financial services, covering a wide range of different activities and thus are 'financial service suppliers' falling under the GATS. Nevertheless, private entities that perform functions usually carried out by central banks or monetary authorities are considered as public authorities when exercising those functions, and thus fall outside the scope of the Financial Services Annex. ${ }^{26}$ Provided that the private entities in question fulfill these criteria, they would most adequately be regarded as supplying a service 'in the exercise of governmental authority', that is neither on a commercial basis nor in competition with one or more service suppliers (Leroux, 2006: 345). However, the services of public or private entities that relate to activities being part of a statutory system of social security or public retirement plans that are supplied in competition with other financial service suppliers would come under the purview of the GATS. This would also apply to activities carried out for the account or with the guarantee or using the financial resources of the national government, as long as other financial service suppliers are also allowed to perform such activities in the marketplace. Because competition would occur between these suppliers offering similar types of financial services, it is understood that public and private entities active in this market carry out for-profit activities and supply services on commercial terms (Leroux, 2006: 354).

While RECs are neither 'goods' nor 'services', RECs trading will involve a series of financial services that financial institutions may supply until a deal for transfer of RECs is concluded, such as brokerage, trust, clearing, and settlement. Consultancies and financial institutions can also offer services relating to derivative product trading, such as price hedging instruments that would allow the seller to secure a future income and the buyer to determine his costs (PriceWaterhouseCoopers, 1999: 73). Such risk management services are usually supplied through forwards, swaps, or options in secondary markets. Certificates can also be offered by their owners as collateral against short-term lending.

A question that arises is whether services related to REC trading would come within the ambit of the category 'new financial services' as defined in the Understanding. This would be a rather broad interpretation that disregards the current structure of the GATS and the depth of the services sectors it already covers. Under entry number 7 of W/120, and in the Financial Services Annex in a more detailed manner, there are several types of financial services that would allow for trading of RECs to be concluded. In the W/120, all financial services that would be involved in trades with RECs are listed under number 7.B f) (Trading). The Financial Services Annex itemizes the relevant financial services in a more comprehensive manner. In paragraph 5(a) of the Annex, as noted earlier, financial services are defined broadly to include 'any service of a financial nature'. An illustrative list of the activities falling under this definition follows. Nevertheless, it is worth noting that the list is so detailed and the financial services at issue so

26 Ibid, para. 5(c)(ii). 
broadly described that is hard to visualize an activity that is not already included in the list, notably as far as 'banking and other financial services' are concerned. ${ }^{27}$

The trading-related financial services are listed under para. 5(a)(x). For our purposes, RECs would most probably fall under $(\mathrm{F})$. Indeed, the nature of this type of certificate, as described earlier, leads to the conclusion that they can be categorized as 'financial assets', or at least, fall under the 'catch-all' category of 'other negotiable instruments'. Para. 5(a)(xiii)-(xvi) also encompasses RECtrading-related services, that is services that will be supplied until a deal is finalized. These include asset management and trust services, settlement and clearing for financial assets, financial information and data processing services, as well as intermediation and other auxiliary services. On the other hand, issuance of certificates would most likely escape the purview of the GATS, as it is typically a task entrusted to public entities within the meaning of paras. 1(b)(iii) and 5(c) of the Financial Services Annex.

The main general obligation that Members have to abide by when it comes to REC trading-related activities is the Most-Favoured-Nation (MFN) principle. Transparency in the form of notifications to the WTO or publication of relevant measures is also a general obligation under certain circumstances described in Article III GATS. For the obligations of market access and national treatment to apply to the transactions relating to trading, Members should have undertaken commitments in the categories of financial services mentioned above. Under GATS, the level of liberalization for each Member is reflected in the number of services sectors that are listed in its Schedule of Commitments in conjunction with the number of restrictions that are embodied therein. Thus, the GATS has a variable scope of application, depending on the Member in question. Nevertheless, notably those Members that adopted the Understanding made comprehensive commitments in most categories of financial services that may relate to the trading of RECs and several of them even allow the cross-border supply of such services. Therefore, respecting market access and national treatment will in most cases be required when financial service suppliers seek to supply such services, notably in the case that these suppliers are established in the WTO Member at issue. Hence quantitative restrictions relating for instance to the total value of service transactions, the number of service operations, or the quantity of output (including total prohibitions amounting to zero quotas) will be inconsistent with the GATS unless otherwise scheduled (Delimatsis and Molinuevo, 2008: 367). As to national treatment, controversy may arise time and again from any differentiation made among foreign and domestic suppliers based on their expertise and the specialized trading services they may provide. Clear-cut criteria for establishing likeness in services remain to be established by the WTO judiciary.

However, most of the measures regulating (or hampering) REC trading will be a subset of domestic financial services regulation. This means that such measures

27 Ibid, para. 5(v)-(xvi). 
will often be non-discriminatory, aiming to ensure the stability, safety, and soundness of the system and thus will fall under the broader category of justified prudential regulation, according to paragraph $2(\mathrm{a})$ of the Financial Services Annex. This would mean that several financial service suppliers may be excluded from providing such services due to fairly demanding (and costly to comply with) requirements relating to available capital, assets, liquidity, or disclosure and reporting. An issue that arises from this conclusion is whether it would be worth envisaging less stringent prudential standards, e.g. lower capital or simplified disclosure and reporting requirements, for those companies that deal exclusively with the supply of financial services in these new areas of trading in certificates or emission rights, as in this case the risks for the financial system are not high.

Furthermore, granting of licenses may be warranted before any entity is allowed to get involved in REC trading. Such licenses could be REC trading-specific, but they can also involve any form of trading services that could exclusively relate to this emerging generation of environment-related products and services. In such cases, the licensing requirements and procedures at issue are typically set by an independent supervisory body, e.g. the national financial services authority. These requirements and procedures would most probably be non-discriminatory and aim to ensure the quality of the service supplied. In this case, Article VI GATS would come into play, which entails certain transparency and due process requirements (Delimatsis, 2007).

The multilateral regulation of trade in financial services is, of course, a peculiar case here because there are sector-specific provisions as set out in the Financial Services Annex to the GATS. Thus, the obligations laid down in Article VI and the relevant disciplines that will be adopted at the end of the Doha Round may be in conflict with the prudential 'carve-out' under the Financial Services Annex. Arguably, licensing requirements aiming to ensure the solvency and the sustainable operation of the entities in question would come under the purview of the prudential 'carve-out', as they are in place to protect investors/consumers, but also to ensure the operability of the system as a whole. Such requirements, however, would also fall under Article VI and the future disciplines with respect to licensing. Additionally, if a necessity test is adopted at the end of the negotiations on domestic regulation under GATS in line with Article VI:4, then governments imposing such requirements may be called upon to defend the necessity of these requirements (Delimatsis, 2008).

The wording of paragraph 2(a) suggests that its function is similar to Article XIV GATS, the general exception provision, and hence it allows for a considerable margin for maneuver to the national regulatory authority when it comes to the adoption and enforcement of such measures. Nonetheless, the second sentence of paragraph 2(a) provides that prudential measures covered under this provision and which are otherwise GATS-inconsistent should not be used as a means of avoiding GATS obligations, that is also those obligations deriving from Article VI such as the obligation to establish review mechanisms for adverse administrative decisions 
laid down in paragraph 2 of Article VI. The test that the WTO judiciary will apply in this case will probably have many similarities to the test of the chapeau of Article XIV in terms of substance, notably this part of the latter test that relates to the decision whether the application of a given measure constitutes a disguised restriction to trade (Cottier et al., 2008).

\section{Conclusion}

Despite the ongoing financial crisis, the international community identifies the need for co-ordinated global action to combat climate change. ${ }^{28}$ The EU, for instance, pledges a $30 \%$ reduction of its GHG emissions by 2020 when compared to the 1990 emissions levels, provided that comparable commitments will be undertaken by other developed and developing countries which significantly contribute to global warming in accordance with the principle of common but differentiated responsibilities and respective capabilities. The new energy plan of the Obama administration now matches or even exceeds the level of ambition of the EU energy security and solidarity action plan. International bodies confirm that it is necessary to set more ambitious emission limits, deeper reductions, and implement measures and policies covering a higher share of global GHG emissions (UNEP Finance Initiative, 2007).

An important component of the Bali Action Plan was the reference to 'enhanced action' to ensure that financial resources and investment to support action on mitigation and adaptation and technology cooperation are provided. The Action Plan calls for improved access to 'adequate, predictable, and sustainable' financial resources and financial innovation that would lead to streamlined funding. ${ }^{29}$ It further underlines the need for mobilizing public- and private-sector funding and investment in clean energy. Only in 2007, new investment in clean energy surpassed US\$148 billion, a $60 \%$ rise when compared to 2006 (UNEP, 2008). This amount accounts for $9.4 \%$ of global energy infrastructure investment and $1 \%$ of global fixed asset investment. With an increase of US\$115 billion in annual investment of RES in the period 2004-2007, it can be plausibly argued that a mobilization of the necessary capital (notably by the private sector) ${ }^{30}$ in order to combat global warming is feasible, as long as the policies chosen favour such a development.

As one can infer, there is a lot of learning-by-doing when it comes to the production of renewable energy and the best scheme to promote it. Governments

28 The G-20 leaders underlined the need to address climate change and energy security despite the ongoing financial crisis. Washington Declaration-Summit on Financial Markets and the World Economy, 15 November 2008.

29 Ibid, para. 1(e).

30 It is worth noting that only $8 \%$ of a total of US\$250-300 billion of energy subsidies worldwide goes to RES subsidisation. Fossil fuels continue to have the lion's share in these subsidies with a total of approx. US\$180-200 billion. UNFCCC Secretariat (2007). 
experiment with several schemes or combinations thereof to find out what may fit best with their domestic conditions. Of course, RECs are only one form of environmental commodity aimed at providing an incentive for the production of electricity from RES. The current state of development in the area of RES can only be regarded as unsatisfactory, as renewable energy accounts for a mere $4.6 \%$ of global power generation (UNEP, 2008: 19).

This article aimed to highlight that, under certain conditions, market-based mechanisms can assist in dealing with climate change, arguably the 'market failure on the greatest scale the world has seen' (Stern, 2006: 27). Innovative marketbased mechanisms such as REC or emission trading come as a recognition that private sector-driven solutions can contribute to the reduction of harmful anthropogenic emissions and the promotion of energy generation by RES. There are important issues to discuss in the near future. One of them is how it would be possible to link such mechanisms to achieve more environment-friendly and costeffective results. Another important issue is how to structure markets dealing with cross-border trade in renewables. There is a strong case for international REC trading and such initiatives have been already launched, albeit on a voluntary basis for the time being. However, the biggest challenge for sustainable energy enterprises seems to be ensuring streamlined financing. Financial innovation becomes even more pressing, as upfront costs for the use of renewables still remain prohibitive. Solar energy, both in developed and developing countries, seems to be the exception to this rule. Market conditions, including entry barriers and the current financial turmoil, have induced consolidation of the industry. Successful raising of capital for small-scale companies and the creation of effective competitive conditions will remain a challenge in this market for the years to come.

Trade rules apply to measures and initiatives that aim to promote renewables and combat climate change. Regarding the GATS, the interest for liberalization in energy services is mounting, as liberalization efforts loom large in the energy sector worldwide and public awareness rises. In this context, Members may be interested to consider in the medium term whether a unified approach regarding energyrelated services and trading of related financial instruments (such as RECs or emission rights) makes sense. A significant argument in favour of this approach would be that, as things now stand with the current classification system, Members may ultimately realize that they have already undertaken commitments in energyrelated sectors, e.g. in financial services, that they had not intended to bind.

\section{References}

Agnolucci, Paolo (2007), 'The Effect of Financial Constraints, Technological Progress and Long-Term Contracts on Tradable Green Certificates', Energy Policy, 35 : 3347-3359.

Allen, Helen, John Hawkins, and Setsuya Sato (2001), 'Electronic Trading and Its Implications for Financial Systems', in Bank for International Settlements (ed.), Electronic Finance: A New Perspective and Challenges, BIS Papers No. 7. 
Bhagwati, Jagdish (1984), 'Splintering and Disembodiment of Services and Developing Nations', The World Economy, 7(2): 133-144.

Capoor, Karan and Philippe Ambrosi (2008), State and Trends of the Carbon Market 2008, World Bank. Claessens, Stijn (2003), 'Regulatory Reform and Trade Liberalization in Financial Services', in A. Mattoo and P. Sauvé (eds.), Domestic Regulation and Service Trade Liberalization, Oxford University Press.

Cottier, Thomas, Panagiotis Delimatsis, and Nicolas Diebold (2008), 'Article XIV GATS', in Rüdiger Wolfrum, Peter-Tobias Stoll, and Clemens Feinäugle (eds.), WTO - Trade in Services, Max Planck Commentaries on World Trade Law, Brill Publishers.

de Witt Wijnen, Rutger (2005), 'Emissions Trading under Article 17 of the Kyoto Protocol', in David Freestone and Charlotte Streck (eds.), Legal Aspects of Implementing the Kyoto Protocol Mechanisms: Making Kyoto Work, Oxford University Press.

Delimatsis, Panagiotis (2007), 'Due Process and "Good" Regulation Embedded in the GATS - Disciplining Regulatory Behaviour in Services through Article VI of the GATS', Journal of International Economic Law, 10: 13-50.

- (2008), 'Determining the Necessity of Domestic Regulations in Services - The Best is Yet to Come', European Journal of International Law, 19: 365-408.

Delimatsis, Panagiotis and Martin Molinuevo (2008), 'Article XVI GATS', in Rüdiger Wolfrum, PeterTobias Stoll, and Clemens Feinäugle (eds.), WTO - Trade in Services, Max Planck Commentaries on World Trade Law, Brill Publishers.

Directive 2001/77/EC of the European Parliament and of the Council of 27 September 2001 on the promotion of electricity produced from renewable energy sources in the internal electricity market [2001], OJ L 283/33, as adapted by the Directive 2006/108/EC relating to the accession of Bulgaria and Romania.

— 2003/87/EC of the European Parliament and of the Council of 13 October 2003 establishing a scheme for greenhouse gas emission allowance trading within the Community and amending Council Directive 96/61/EC [2003], OJ L 275/32, as amended by the Directive 2004/101/EC.

-2004/39/EC of the European Parliament and of the Council of 21 April 2004 on markets in financial instruments amending Council Directives 85/611/EEC and 93/6/EEC and Directive 2000/12/EC of the European Parliament and of the Council and repealing Council Directive 93/22/EEC [2004], OJ L $145 / 1$.

Dobson, Wendy and Pierre Jacquet (1998), Financial Services Liberalization in the WTO, Institute for International Economics Press.

Dornau, Robert (2005), 'The Emissions Trading Scheme of the European Union', in David Freestone and Charlotte Streck (eds.), Legal Aspects of Implementing the Kyoto Protocol Mechanisms: Making Kyoto Work, Oxford University Press.

Eschenbach, Felix, Joseph Francois, and Ludger Schuknecht (2000), 'Financial Sector Openness and Economic Growth', in Stijn Claessens and Marion Jansen (eds.), The Internationalisation of Financial Services: Issues and Lessons for Developing Countries, Kluwer Law International.

European Commission (2008a), 'Proposal for a Directive of the European Parliament and of the Council on the Promotion of the Use of Energy from Renewable Energy Sources', COM(2008) 19 final.

European Commission (2008b), '20 20 by 2020: Europe's Climate Change Opportunity', COM(2008) 30 final.

Evans, Peter (2003), 'Strengthening WTO Member Commitments in Energy Services: Problems and Prospects', in Aaditya Mattoo and Pierre Sauvé (eds.), Domestic Regulation and Service Trade Liberalization, Oxford University Press.

Freestone, David (2005), 'The UN Framework Convention on Climate Change, the Kyoto Protocol, and the Kyoto Mechanisms', in David Freestone and Charlotte Streck (eds.), Legal Aspects of Implementing the Kyoto Protocol Mechanisms: Making Kyoto Work, Oxford University Press.

GATT (1991), 'Services Sectoral Classification List', MTN.GNS/W/120.

Gillenwater, Michael (2008a), 'Redefining RECs (Part 1): Untangling attributes and offsets', Energy Policy, 36(6): 2109-2119. 
- (2008b), 'Redefining RECs (Part 2): Untangling certificates and emission rights', Energy Policy, 36(6): 2120-2129.

Gilligan, George (1999), Regulating the Financial Services Sector, Kluwer Law International.

Green, Andrew (2005), 'Climate Change, Regulatory Policy and the WTO - How Constraining are Trade Rules?', Journal of International Economic Law, 8(1): 143-189.

Holt, Ed and Lori Bird (2005), 'Emerging Markets for Renewable Energy Certificates: Opportunities and Challenges', National Renewable Energy Laboratory (NREL) Technical Report.

Holt, Ed and Ryan Wiser (2007), 'The Treatment of Renewable Energy Certificates, Emissions Allowances, and Green Power Programs in State Renewables Portfolio Standards', available at: http://eetd.lbl.gov/ea/ems/reports/62574.pdf (accessed September 2008).

Intergovernmental Panel on Climate Change (IPCC) (2007), Climate Change 2007: Synthesis Report. International Energy Agency (IEA) (2007), World Energy Outlook 2007.

Key, Sydney (2005), 'Financial Services', in Patrick F. J. Macrory, Arthur E. Appleton, and Michael J. Plummer (eds.), The World Trade Organization: Legal, Economic and Political Analysis, Volume I, Springer.

Leroux, Eric (2006), "What is a "Service Supplied in the Exercise of Governmental Authority" Under Article I:3(b) and (c) of the General Agreement on Trade in Services?', Journal of World Trade, 40(3): 345-386.

Mattoo, Aaditya, Rathindran Randeep, and Arvind Subramanian (2006), 'Measuring Services Trade Liberalization and Its Impact on Economic Growth: An Illustration', Journal of Economic Integration, 21(1): 64-98.

Menanteau, Philippe, Dominique Finon, and Marie-Laure Lamy (2003), 'Prices Versus Quantities: Choosing Policies for Promoting the Development of Renewable Energy', Energy Policy, 31(8): 799-812.

Meyer, Niels (2003), 'European Schemes for Promoting Renewables in Liberalized Markets', Energy Policy, 31(7): 665-676.

Mitchell, Catherine, Dierk Bauknecht, and Peter Connor (2006), 'Effectiveness through Risk Reduction: A Comparison of the Renewable Obligation in England and Wales and the Feed-In System in Germany', Energy Policy, 34(3): 297-305.

Morthorst, Poul Erik (2000), 'The Development of a Green Certificate Market', Energy Policy, 28(15): 1085-1094.

- (2001), 'Interactions of a Tradable Green Certificate Market with a Tradable Permits Market', Energy Policy, 29(5): 345-353.

NERA Economic Consulting (2005), 'Interactions of the EU ETS with Green and White Certificate Schemes: Summary Report for Policy Makers', Study commissioned by the European Commission DG Environment.

Point Carbon (2008), 'Carbon Market Transactions in 2020: Dominated by Financials?', available at: www.pointcarbon.com (accessed September 2008).

PriceWaterhouseCoopers (1999), 'Organisation of RE Market and Trading of Green Certificates'.

REN21 (2007), Renewables 2007: Global Status Report.

Roy, Martin, Juan Marchetti, and Aik Hoe Lim (2008), 'The Race towards Preferential Trade Agreements in Services: How Much Market Access is really Achieved?', in Marion Panizzon, Nicole Pohl, and Pierre Sauvé (eds.), GATS and the Regulation of International Trade in Services - World Trade Forum, Cambridge University Press.

Söderholm, Patrik (2008), 'The Political Economy of International Green Certificate Markets', Energy Policy, 36(6): 2051-2062.

Stern, Nicolas (2006), The Economics of Climate Change-The Stern Review, Cambridge University Press.

UNCTAD (2001), 'Energy Services in International Trade: Development Implications', TD/B/COM.1/ EM.16/2.

United Nations Environment Programme (UNEP) Finance Initiative (2002), Climate Change and the Financial Services Industry - Threats and Opportunities.

- (2007), Declaration on Climate Change by the Financial Services Sector. 
United Nations Environment Programme (UNEP) (2007), Global Environmental Outlook (GEO 4) - Environment for Development.

- (2008), 'Global Trends in Sustainable Energy Investment 2008 - Analysis of Trends and Issues in the Financing of Renewable Energy and Energy Efficiency'.

UNFCCC Secretariat (2007), 'Energy Subsidies: Their Magnitude, How they Affect Energy Investment and Greenhouse Gas Emissions, and Prospects for Reform'.

Verhaegen, Karolien, Leonardo Meeus, and Ronnie Belmans (2005), 'Towards an International Certificate System - The Stimulating Example of Belgium', in Kurt Deketelaere, Janet Milne, Larry Kreiser, and Hope Ashiabor (eds.), Critical Issues in Environmental Taxation: International and Comparative Perspectives, Volume IV, Oxford University Press.

Wemaere, Matthieu and Charlotte Streck (2005), 'Legal Ownership and Nature of Kyoto Units and EU Allowances', in David Freestone and Charlotte Streck (eds.), Legal Aspects of Implementing the Kyoto Protocol Mechanisms: Making Kyoto Work, Oxford University Press.

Wilkinson, Rorde (1995), 'The Uruguay Round and Financial Services', in Jacques Bourgeois, Frédérique Berrod, and Gippini Fournier (eds.), The Uruguay Round Results: A European Lawyer's Perspective, European Interuniversity Press.

Wilder, Martijn (2005), 'Can Companies or Entities from a Non-Party to the Kyoto Protocol Participate in the Flexible Mechanisms?', in David Freestone and Charlotte Streck (eds.), Legal Aspects of Implementing the Kyoto Protocol Mechanisms: Making Kyoto Work, Oxford University Press.

Woodrow, Brian (2000), 'The 1997 World Trade Organization Accord on Financial Services: Its Impact and Implications for the World Insurance Industry', The Geneva Papers on Risk and Insurance, 25(1).

WTO (1997), 'Fifth Protocol to the General Agreement on Trade in Services', S/L/45.

_ (1998a), 'Energy Services', Background Note by the Secretariat, S/C/W/52.

— (1998b), 'Financial Services', Background Note by the Secretariat, S/C/W/72.

- (2002), 'Additional Commitments under Article XVIII of the GATS', S/CSC/W/34, 2002.

— (2005), 'Liberalization of Financial Services', Communication from Australia et al., TN/S/W/43, $\mathrm{S} / \mathrm{FIN} / \mathrm{W} / 43$. 